\title{
El romancillo de El bonetero, Juan de Mena y la tradición oral
}

\author{
A Cástor Portugués, amigo y cantor de \\ mi primer "Bonetero".
}

Quizás no sea la anécdota de un hombre engañado en la compra de un caballo cojimanco y tropezador la que uno se imaginaría, en principio, dando cuerpo a uno de los ejemplos más interesantes - y de los que más atención han atraído- del romancero español. $\mathrm{Y}$, sin embargo, esa anécdota es la del romancillo de El bonetero, del que se ha descrito una trayectoria literaria tan curiosa y atractiva como puede ser la que va desde el teatro de Calderón o desde un poemario prologado por Gracián hasta el folclore actual de España o de los sefardíes de Marruecos y de Oriente.

El hilo que une estos jalones ha sido urdido en varios trabajos de Diego Catalán y de Jesús Antonio Cid ', valedores de la incorporación de la, en apariencia, insustancial fábula a los anales de la mejor estudiada literatura: mejor estudiada en el doble sentido de más profundamente documentada y analizada, y de más abierta a las nuevas pesquisas e interpretaciones que un campo como el de la literatura oral nunca cierra. Ambos trabajos serán referencia inexcusable de éste, que, sin embargo, debe adentrarse en la materia por épocas y problemas distintos.

UNAS COPLAS QUE HIZO JUAN DE MENA SOBRE UN MACHO QUE COMPRO DE UN FRAILE Y DOS CARTAS INVENTADAS DEL BACHILLER DE CIBDAREAL

Uno de los poemas de Juan de Mena que mayor favor popular debió alcanzar en el Renacimiento fue la larga composición titulada Coplas que bizo Juan de Mena sobre un macho que compró de un fraile, en

1 D. CATALÁN, «Una jacarilla barroca, hoy tradicional en Extremadura y en Oriente», Revista de Estudios Extremeños, VIII (1952), pp. 377-387; ampliado con el título de «Vida oral de la poesía culta en metros fáciles: El bonetero de la Trapería», en Por campos del romancero (Madrid, 1970), pp. 283-301; y J. A. CiD, «Calderón y el romance de El bonetero de la Trapería", Hispanic Review, XVL (1977), pp. 421-434. A ambos maestros y amigos, y a I. M. Hassán, P. Díaz Más, y J. C. Conde deseo agradecer la lectura y las eventuales indicaciones y correcciones aportadas a este artículo. 
las que la descripción de la venta abusiva de un caballo servía para satirizar la avaricia del clero. La aparición de ediciones en 1512, 1528, 1552 y 1582 , y la certeza que se tiene de la pérdida de otras ${ }^{2}$, son síntoma de una aceptación popular que, sin embargo, y por lo que muestran estos textos, no parece se viera acompañada de un apreciable desarrollo de variantes ni, por tanto, de una efectiva tradicionalización. Conozcamos las primeras ocho de sus quince coplas octosilábicas, según la edición que ha hecho Miguel Ángel Pérez Priego a partir de una edición de 1528:

I ¿Quál diablo me topó con este cabezpacido? ¿Quál diablo me robó tan aína mi sentido? Que si yo más cuerdo fuera y por él no me creyera, castigarme deviera lo que d' él avía oído.

II Un arcipreste malvado, que me vido de partida, con un macho m' a engañado, qual sea negra su vida. Yo no digo que es harón ni que le toma torçón, mas porfía por un son qu' el espuela se le olvida.

III El fraile, sancto, cortés, bien jurava qu' era sano: él coxquea de tres pies y no hinca la una mano. Mas con todas estas plagas, sobrehuesso y axuagas, la boca llena de llagas, es verdad que anda llano.

IV Çanquituerto y rodilludo lo hizieron sus pecados, con sus dientes asserados bien come y no es agudo. No digo que es chica pieça

2 Ver sobre sus fuentes y ediciones, de M. A. Pérez Priego, Juan de Mena: obra lírica (Madrid, 1979), pp. 54 y 237-238. 
ni que tiene gran cabeça, ni tampoco que tropieça, mas cae bien a menudo.

V Despalmado, y otros tales cient mil daños encubiertos él tiene bien, por los quales mil machos devían ser muertos. Mas verés en sus costillas qu' él sabe de muchas sillas, después fechas las rodillas de rezar a cabos ciertos.

VI Pero yo no me curava, aunque lo vi $\tan$ cenceño, ca yo mucho confiava en las juras de su dueño. Mas en la mercadería tanta fue su cortesía, que dos noches con un día me hizo perder el sueño.

VII Finalmente ya contento en dineros, no en papel, yo tomélo a pagamiento, y anduve una legua en él, y más lo que Dios se quiso; mas de tanto vos aviso: que me fallé tan repiso que pensé bolver sin él.

VIII Quando ya pude tornallo, mal o bien me di al trasache; raviando por embiallo, dixe al moço que despache:

«Toma, toma este diablo, mételo en el establo de aquel que vi en un retablo pintado por homarrache»... ${ }^{3}$.

3 Reproduzco el texto editado por Pérez Priego en Juan de Mena: obra lírica, pp. 237-243, al que remito para consultas léxicas y de variantes. Ver también el comentario literario en pp. 42-43; y PÉREZ PRIEGo, Juan de Mena: obra completa (Barcelona, 1989), pp. 100 y ss. Para las antologías que publican estas Coplas, ver C. de NigRs, Juan de Mena: poesie minori (Nápoles, 1988), pp. 421 y ss. 
En las siete coplas conclusivas que omito se relata un desenlace favorable para el engañado protagonista, quien logra llevar ante un jurado al clérigo estafador y recuperar su dinero, para advertir finalmente: «Guardaos todos, guardad, / de personas tan maldichas, / y del mulo del abad / con sus tachas sobredichas.»

El recuerdo de estas Coplas debió perdurar, ya que en el siglo XVII (según la fechación de Emil Gessner, Carolina Michäelis de Vasconcellos y M." Rosa Lida de Malkiel) o en el XVIII (según la de Pérez Priego) se hacía alusión a ellas en dos de las «cartas» que componen el fantasioso Centón epistolario del llamado Bachiller Fernán Gómez de Cibdareal, del que hoy no queda duda de que fue un tardío falsificador barroco del estilo y del ambiente histórico-cultural del siglo $\mathrm{XV}^{4}$. El carácter apócrifo de las referencias que a Juan de Mena y a sus Coplas se hacen en estas «cartas» ha recibido el siguiente comentario de Pérez Priego:

Estas coplas dieron pie a dos cartas inventadas del Bachiller de Cibdareal (Centón epistolario, Madrid, 1775). En la Epístola XXXIII se queja al rey de que «la mula que me donó Pero Manrique ella ha tan malvadas mañas como el macho que compró Juan de Mena del Arcipreste de Mojados» [está fechada en Trujillo, 1429; esto es, cuando Mena tendría dieciocho años, lo que viene a corroborar la inautenticidad de la carta]. En la Epistola XXXVI, de la misma fecha, se dirige al propio Mena preguntándole «si el macho que del Arcipreste comprastes era de pelo pardo, lagrimón del ojo izquierdo, e cálido de riñones, e si por esto amagaba de meterse en todos los charcos, e tropezador de a cada diez estropiezos enfilar una caída: ca si estas eran sus mañas, el macho vino a poder del Adelantado, e me lo donó para que ficiese el camino a buscar al Condestable» ${ }^{5}$.

Al margen, por ahora, de los demás problemas que plantean estas Coplas y sus alusiones en este falso Centón epistolario, conviene retener diversos detalles sobre los que habremos de volver: por ejemplo, la declaración de Mena de que las tachas del caballo eran asunto que ya «avia oido» el poeta antes de comprarlo (v. 8); y rasgos de su descripción física como los de que «coxquea de tres pies / y no hinca la una mano» (vs. 19-20), tenía "plagas, / sobrehuesso y axuagas, / la boca llena de llagas» (vs. 21-23), o «cae bien a menudo» (v. 33). Con-

* Ver la discusión sobre el tema en MiChäElIS DE VASCONCEllos, «Zur CibdárealFrage», Romanische Forschungen VII (1891), pp. 75-89, donde se hallarán constantes referencias a Gessner -agradezco la comunicación del dato y la entrega del artículo a J. A. Cid-; y ver además M.a R. LIDA DE MALKIEL, Juan de Mena, poeta del prerrenacimiento español (México, 1950), Pp. 345-346; y PÉRez PRIEgo, Juan de Mena: obra lírica, pp. 3-4.

Juan de Mena: obra lírica, p. 243, nota 124. 
vendrá además fijarse en las pullas que le dedica el Bachiller de Cibdareal cuando dice que «amagaba de meterse en todos los charcos, e tropezador de a cada diez estropiezos enfilar una caída», ya que plantean una cuestión nada irrelevante: si Mena no alude a la inclinación de su macho a «meterse en todos los charcos» ¿por qué sí mencionó este detalle, poniendo énfasis además sobre su facilidad tropezadora, el falsificador del siglo XVII? Posiblemente porque el Bachiller de Cibdareal conocía -e identificaba y confundía con el de Mena- otro caballo que sí que mostraba una irrefrenable tendencia a meterse en los charcos.

\section{EL ROMANCILLO DE EL BONETERO EN EL SIGLO XVII Y EN EL FOLCLORE MODERNO DE CÁCERES Y DE LOS SEFARDÍES DE MARRUECOS Y ORIENTE}

Tal caballo nos sale al paso en un romancillo satírico que se ha mantenido en la tradición oral desde el Siglo de Oro hasta hoy y que presenta un animal que además de estar siempre tropezando en charcos, era «de los tres pies coxo y el otro quebrado», como el de Mena. Conozcamos, tal como la editó Cid, la versión del romancillo incluida por Calderón en su comedia El alcaide de sí mismo (anterior a 1636), en la que se dice que la entonaban los rústicos Antona y Benito «quando a los montes $\mathrm{iba}[\mathrm{n}]$ a trabajar»:

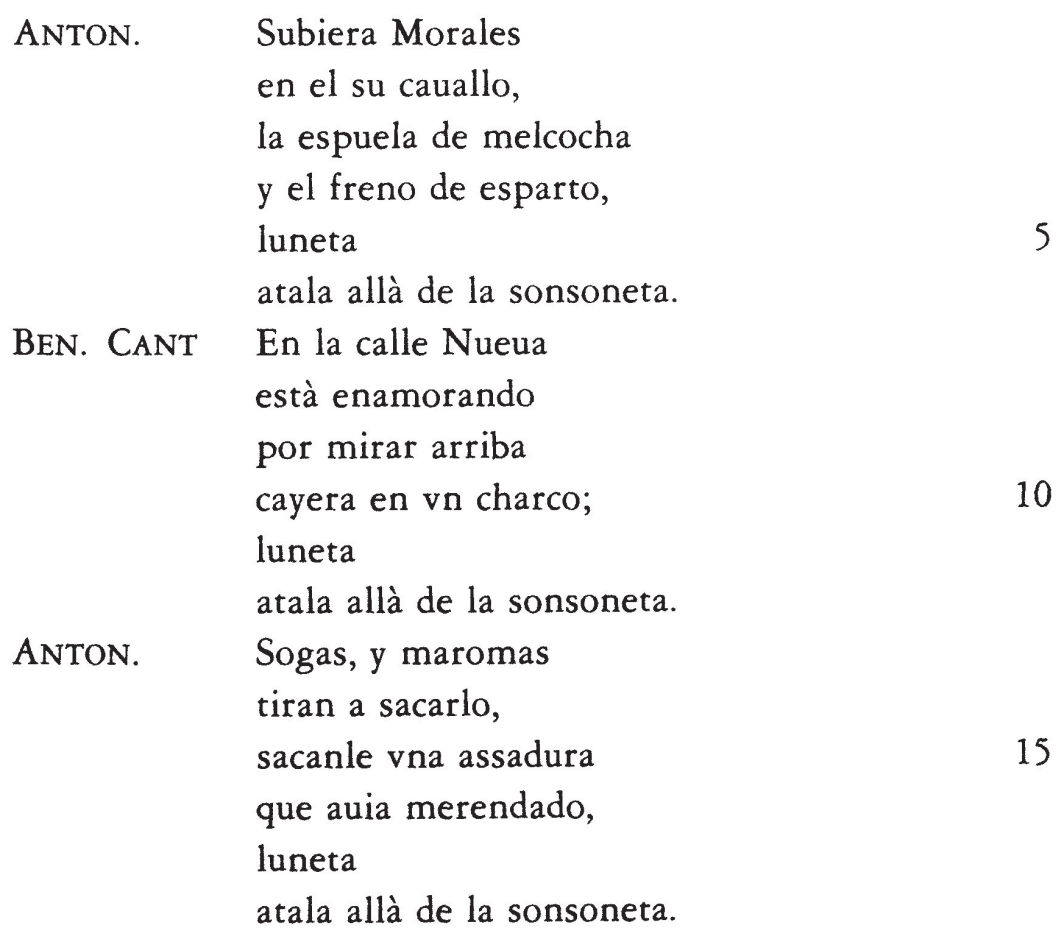


En 1654 aparecía en Zaragoza una variante del mismo poema, dentro de una colectánea de Poesías varias de grandes ingenios españoles publicada por Josef Alfay, con la colaboración y prólogo de Gracián. Es así como la editó Catalán:

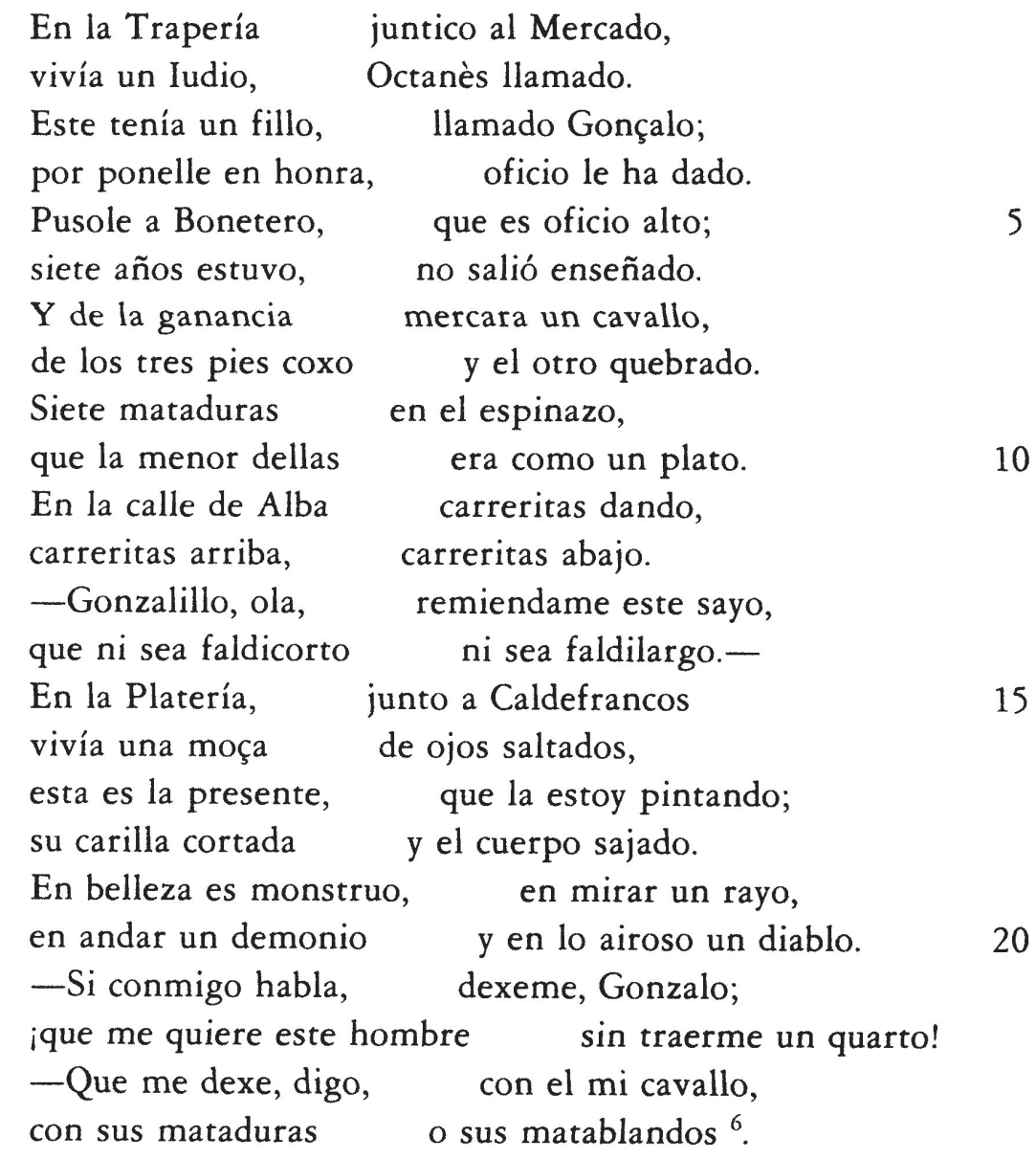

Evidente relación hay entre este romancillo barroco de contenido antijudío y este otro que se canta aún hoy en el pueblo cacereño de Arroyo de la Luz:

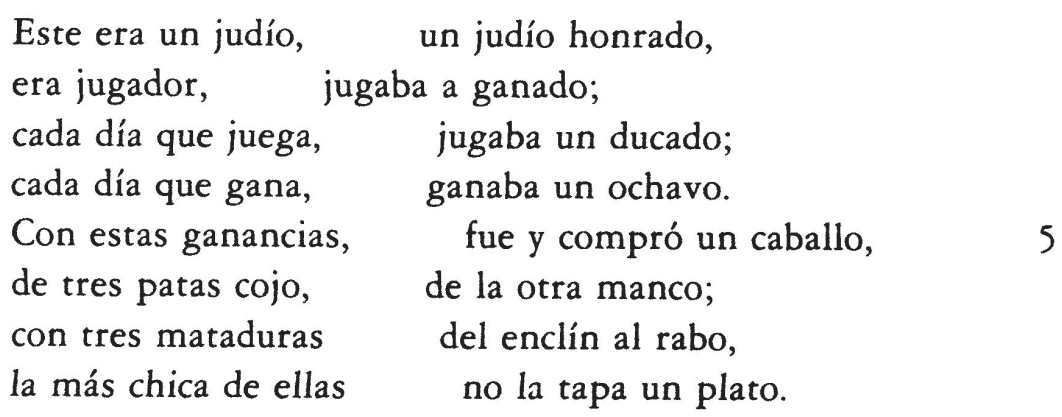
mistiquio. 
Lo sacan un día tropezó en un llano, Fueron los judíos unos llevan sogas, unos sacan tripa, Estas son ganancias a comer al prado, fue a caer a un charco.

a saná el caballo; otros soga-garcio; otros tripa-cuajo. de judío honrado ?

Precisamente por el contenido antijudío de estos testimonios españoles sorprende que el romancillo se haya mantenido también en el repertorio oral de los sefardíes de Oriente y de Marruecos, en los que, lógicamente, se omiten las referencias antijudías. En una versión recogida por Alberto Hemsi en Estambul, el protagonista no era hijo de un judío, sino de un rey:

El rey tenía un hijo,
Oficio no tenía,
Gana que gana,

Ancho le vino, estrecho le vino, le cortó del lado.

Luengo le vino, curto le vino, le cortó de abajo. 5

Corta que corta, se quedó sin sayo.

Un día de los días se mercó un caballo... ${ }^{8}$.

En los testimonios de los judíos de Marruecos, además de omitirse también todo eco de referencia antijudía, se llega incluso a «volver al

7 B. GIL, Romances populares de Extremadura (Badajoz, 1944), p. 103. Otras versiones de este pueblo han sido publicadas en K. SCHINDlER, Folk Music and Poetry of Spain and Portugal (N. York, 1941), núm. 216; V. GutiérRez MaCf́as, «Fiestas cacereñas», RTDP, XVI (1960), pp. 335-357: p. 341; A. CAPDEVIELLE, Cancionero de Cáceres y su provincia (Madrid, 1969), p. 93; F. GARCía REDONDO, Cancionero arroyano (Cáceres, 1985), pp. 52-53; y J. M. Fraile, Romances y canciones de Arroyo de la Luz [disco Tecnosaga, 1985], I/B2.

8 A. Hemsi, Coplas sefardíes, IX (Estambul, 1933), núm. LIV. Ver la reseña de S. G. Armistead y J. H. Silverman, «Sobre las Coplas sefardies de Alberto Hemsi», Estudios sefardies, 3 (1980), pp. 423-447: p. 438. Textos de Bosnia fueron publicados en CATALÁN, op. cit. y en S. M. ElAZAR, El romancero judeo-español (Sarajevo, 1987), p. 52; otro de Salónica en el Cancionero de Hemsi editado por E. Seroussi, con la colaboración de P. Díaz-Mas, J. M. Pedrosa, y E. Romero (Jerusalén, 1992), núm. 65. Ver más datos sobre los textos sefardíes en ARMISTEAD y Silverman, Romances judeoespañoles de Tánger recogidos por Zarita Nahón (Madrid, 1977), núm. 65; y ARMISTEAD y otros, El romancero judeo-español en el Archivo Menéndez Pidal: Catálogo-Indice de romances y canciones (Madrid, 1978), núm. X.10. Hay otra versión turca, fragmentaria e inédita, en el Proyecto Folklor de la Radiodifusión Israelí (PF 014/09). 
revés» el sentido del romancillo y a convertir en cristiano a su ridículo protagonista:

Por calle Sevilla moraba un cristiano, cortaba y cusía con deçiplos cuatro...

De todos estos materiales extrajeron Catalán y Cid conclusiones que se pueden resumir en su opinión de que las versiones del siglo XVII debieron ser recogidas de la tradición oral, de la que son síntomas su estribillo, sus irregularidades métricas y sus incongruencias argumentales; la fecha de su composición no debió ser muy anterior, de todas formas, a la de su documentación en 1636 y en 1654, ya que la voz «fillo» documentada en uno de aquellos textos ha de ser un portuguesismo sugeridor de que Octanès y su hijo pudieron ser de los «cristianos nuevos» portugueses que se asentaron en Castilla en el segundo cuarto del siglo XVII, dato que se ve reforzado por el hecho de que «el oficio de bonetero o sastre remendón, que le atribuyen la versión del siglo XVII... [y otras] era desempeñado muy comúnmente por cristianos nuevos». Llega incluso a apuntar Catalán, a este respecto, la posibilidad de que «las abundantes precisiones en la topografía ciudadana (Trapería junto al Mercado, calle de Alba; Platería junto a Caldefrancos) sitúan la acción en un lugar evidentemente determinado; es muy probable que el romancillo aluda a un sucedido concreto, y que el poeta ejercitase su ingenio, mordaz y festivo, a costa de unos prójimos conocidos». En el contexto de esa intención satírica de hechos y personajes conocidos podrían quizá entenderse los episodios de la actividad remendona del protagonista y de la endiablada moza de la Platería que se documentan en 1654, y que, según Catalán, debieron constituir originariamente el «tema central del poema burlesco». Cid abunda en lo mismo, al señalar sobre la versión de Alfay-Gracián que sus referencias toponímicas (la Trapería, calle de Alba, la Platería, Caldefrancos) parecen situar la fábula en el escenario urbano de Sevilla. En cualquier caso, a Catalán le parece tan indudable la filiación barroca del romancillo que afirma que "proporciona un nuevo ejemplo de cómo los sefardíes orientales siguieron recibiendo romances de España nacidos en tiempos muy posteriores a su expulsión de la Península». 


\section{EL ROMANCILLO DE EL BONETERO EN LA TRADICIÓN CASTELLANA DE ZAMORA, LEÓN Y PALENCIA}

Uno de los mayores atractivos que tenía hasta hace poco el romancillo de El bonetero era el de la exigüidad de su documentación en el folclore de la Península, que sólo nos ofrecía los testimonios recogidos en Arroyo de la Luz. Desde hace una década se han publicado otras versiones que arrojan nueva luz sobre determinados aspectos de su vida oral. Una zamorana, publicada en 1987 aunque fue recogida a comienzos del siglo $\mathrm{XX}$, comienza así:

$\begin{array}{ll}\text { Era un bonetero } & \text { portugués honrado. } \\ \text { Haciendo bonetes } & \text { ganaba el ochavo. } \\ \text { Con aquel ochavo } & \text { se cumpró un caballo, } \\ \text { cojo de tres patas, } & \text { de una ritancriado... }\end{array}$

También de tierras leonesas se han recogido y publicado en los últimos años versiones de tipo similar al zamorano ${ }^{10}$. $\mathrm{Y}$ del pueblo palentino de Vega de doña Olimpia recogí yo otra versión en 1990:

\begin{tabular}{|c|c|}
\hline $\begin{array}{l}\text { Era un zapatero } \\
\text { que hacía bonetes, } \\
\text { que con el dinero, } \\
\text { Madrugar un día, } \\
\text { Tropezó en un junco, } \\
\text { Los perros decían: } \\
\text { Los amos perdieron, }\end{array}$ & $\begin{array}{l}\text { y un marqués honrado } \\
\text { les vendía a ochavo, } \\
\text { compraría un caballo. } \\
\text { y llevarle al prado. } \\
\text { cayó en un fontano. } \\
\text { - En buen año estamos. } \\
\text { nosotros ganamos }{ }^{11} \text {. }\end{array}$ \\
\hline
\end{tabular}

9 S. Calabuig laguna, Cancionero zamorano de Haedo (Zamora, 1987), p. 525.

10 Ver versiones de Val de San Lorenzo en Fraile, De encuesta por León y Asturias: II Val de San Lorenzo, Filiel, Chana de Somoza (Madrid, 1985) [disco Saga VPC172] A/4; y Antología sonora del romancero panbispánico (Salamanca, 1991), 5/B1 (publicada además en Romancero general de León, eds. CATALÁN, M. de la CAMPA et al., 2 vols., Madrid, 1991, II, pp. 352-3); y en M. MANZANO, Cancionero leonés (León, 1988), vol. I, núm. 276; hay dos versiones de Calzada de la Valdería y Villaverde la Chiquita, recogidas por los equipos de la Cátedra Seminario Menéndez Pidal, en Romancero general de León, II, pp. 353-354; y otras dos de Villamuñío y Villamarco recogidas por mí, en Romancero general de León, II, pp. 354 y 355. Poseo otras versiones inéditas recogidas en estos pueblos, en encuestas realizadas entre 1989 y 1992, en compañía de Marta Nistal, Rocío Rodríguez, Margit Frenk y César Palacios.

11 Versión PRT 751 en mi catálogo, cantada por una mujer de nombre desconocido y 57 años de edad, que la aprendió de su abuelo. Fue entrevistada en Villota del Duque (Palencia) el 21-7-1990. Se repiten ambos hemistiquios. Antes y después de la repetición del segundo se cantan los estribillos «cacafú» y «morenà». 
EL ROMANCILlO DE EL BONETERo EN LA TRADICIÓN DE FUENTE DEL MAESTRE (BADAJOZ)

Una nueva versión de $E l$ bonetero recogida en el pueblo pacense de Fuente del Maestre fue publicada en 1989 por Jesús Lozano, quien, desconocedor del venerable currículum de la composición, pensaba que sus referencias a lugares y personas bien conocidas del pueblo sugerían el «origen fontanés» de este «romance de zambomba». Aunque esto no sea así, sus citas localistas autorizan por lo menos a hablar de «recreación» auténticamente fontanesa:

\begin{tabular}{|c|c|}
\hline $\begin{array}{l}\text { En la calle Nueva } \\
\text { jugador de naipes }\end{array}$ & $\begin{array}{l}\text { vivía un gitano, } \\
\text { muy afortunado. }\end{array}$ \\
\hline $\begin{array}{l}\text { Cada vez que pierde } \\
\text { y si acaso gana, } \quad \mathrm{g}\end{array}$ & $\begin{array}{l}\text { pierde dos ducados, } \\
\text { gana dos ochavos. }\end{array}$ \\
\hline $\begin{array}{l}\text { Con tantas ganancias } \\
\text { con tres matauras } \\
\text { Y le echó una leva }\end{array}$ & $\begin{array}{l}\text { se ha mercao un jaco, } \\
\text { de la oreja al rabo. } \\
\text { por la sierra abajo. }\end{array}$ \\
\hline $\begin{array}{l}\text { Trompesó en un berro, } \\
\text { Acudid, gitanos, }\end{array}$ & $\begin{array}{l}\text { se encajó en un charco. } \\
\text { que se cayó el jaco. }\end{array}$ \\
\hline $\begin{array}{l}\text { Allá va Cristóbal, } \\
\text { y las dos orejas, } \\
\text { de tantos tirones }\end{array}$ & $\begin{array}{l}\text { detrás va Gervasio, } \\
\text { las patas y el rabo } \\
\text { se las arrancaron. }\end{array}$ \\
\hline $\begin{array}{l}\text { Al día siguiente } \\
\text { y otro nuevo jaco }\end{array}$ & $\begin{array}{l}\text { se encontró un real } \\
\text { se ha vuelto a comprar }{ }^{12} \text {. }\end{array}$ \\
\hline
\end{tabular}

En una encuesta realizada en este pueblo encontré versiones más breves del romancillo, y supe que «la calle Nueva» (¿coincidencia casual con la «calle Nueua» de Calderón?), pese a haber cambiado hace tiempo su nombre por el de «calle de Ramón y Cajal», era bien conocida en el pueblo. En ella habían vivido siempre muchos gitanos, entre ellos los dos que se citan en la versión anterior del romancillo - Cristóbal y Gervasio- o el que se cita en una recogida por mí - Gaspar-. Todos ellos debieron ser auténticos «tipos característicos» del pueblo, donde se les sigue recordando alrededor de cincuenta años después de su muerte. Reproduzco tres de las versiones del romancillo que recogí en este pueblo:

12 J. Lozano, «Coplas de zambomba (tradición popular fontanesa)», Antropología cultural de Extremadura: Actas de las Primeras Jornadas de Cultura Popular (Mérida, 1989), pp. 639-653: pp. 646-647. Se canta con el estribillo «Y dale gandún, / gandún galandario. / Y búscalo tú / que yo no lo hallo» tras cada verso. 
En la calle Nueva vivía un gitano,

y en $c a^{\prime}$ vez que venía la feria, ganaba un ochavo.

Con aquella ganancia y compró un caballo.

Tenía una matadura de la oreja al rabo,

y lo echó a correr

Tropezó en un berro

un arroyo abajo.

y los perros de Gaspar

y cayó en un charco,

lo sacaron a peazos.

En la calle Nueva

vivía un gitano.

Cada vez que ganaba

ganaba un ochavo,

y cada vez que perdía,

Con estas ganancias perdía un ochavo.

que tenía una matadura

compró un caballo, de la cabeza al rabo.

En la calle Nueva

vivía un gitano,

jugador de naipes

muy aficionado.

Cada vez que perdía,

perdía un ducado,

cada vez que ganaba,

Con estas ganancias

ganaba un ochavo

con una mataura

ha comprado un jaco,

y lo echó a correr

de la oreja al rabo,

Trompesó en un berro

una cuesta abajo.

y se cayó en un charco ${ }^{13}$.

\section{¿UNA REFUNDICIÓN DE EL BONETERO SE INTERPOLABA EN UNA REPRE- SENTACIÓN DE LA MUERTE DEL GALLO DE GUAdILla DE VILlaMAR (BURGOS)?}

En una representación de $E l$ reinado o de La muerte del gallo que se celebraba en los carnavales del pueblo burgalés de Guadilla de Villamar, diversos muchachos y muchachas disfrazados de Rey, Capitán, etc., declamaban la sentencia y muerte del gallo. Entre ellos había también un Bobalicón Extremeño que culminaba su grotesco monólogo con lo que parece ser una descripción del caballo de $E l$ bonetero vertida curiosamente en un metro (octosílabo) y en una asonancia (en é.o) diferentes de los habituales.

Yo soy el Bobalicón cántara y media de vino que vengo de Extremadura; me he bebido hoy en ayunas,

13 Versiones PRT 661, 663 y 665, recitadas el 28-6-1990 por Gabriel Sánchez, de 81 años; Dionisio Sánchez, de 74; y Fernando García (n. 1907). La segunda versión se cantaba con el estribillo «Y dale gandún, / gandún, galundario, / y búsquela usted, / que yo no la hallo» después de cada verso; y la tercera, con el estribillo anterior, o con otro terminado en «... / señor boticario». 
cien varas de longaniza, la pechuga de una pava, las asaduras de un macho, Con eso no digo más, Hallé las puertas cerradas, eché mano a mi terciada no quedó diablo ni diabla sino más que un Satanás con un cordel en la mano porque echaba agua en el vino lo compraba a cuatro cuartos, Dios le dé tanta salud siete años tuvo la sarna, siete mataduras tuvo la menor como una olla, y al cabo de los cincuenta al pie de quinientos huevos,

los lomillos de un carnero,

y las turmas de un becerro.

que me voy para el infierno.

que me las negó el portero,

y de allí se fueron luego;

que no huyera al momento, más negro que un calderero,

azotando al tabernero, y lo vendía como bueno, lo vendía a real y medio.

como al mi borrico viejo:

otros siete tuvo muermo, desde el rabo hasta el pescuezo,

la mayor como un caldero, me lo comieron los perros ${ }^{14}$.

EL EPISODIO DE LA MOZA ENDEMONIADA SE INTERPOLABA EN UN «DANCE» TRADICIONAL DE QUINTO DE EBRO (ZARAGOZA)

Se recordará que en la versión de $E l$ bonetero de la edición de Alfay-Gracián (1654) se engarzaba un pasaje referido a una «moza endemoniada» que no figuraba en los demás textos, aunque Catalán pensaba que había pertenecido al núcleo originario del poema.

... En la Platería, vivía una moça esta es la presente, su carilla cortada En belleza es monstruo, en andar un demonio -Si conmigo habla, junto a Caldefrancos de ojos saltados, que la estoy pintando;

\section{y el cuerpo sajado.}

y en lo airoso un diablo.

dexeme, Gonzalo...

Hete aquí que nuestra moza endemoniada asoma en un «dance» que todavía a mediados del siglo $\mathrm{xX}$ se representaba en el pueblo zarago-

14 J. de la FUENTE, «El reinado», RDTP, I (1944), pp. 339-345: pp. 344-345. Una versión sin el desenlace del borrico, está en S. H. Petersen, Catalán y otros, Voces nuevas del romancero castellano leonés: A.I. E. R. (Madrid, 1982), vol. II, núm. 134. Otra sólo de la muerte del borrico, en L. Díaz Viana, M. Manzano y otros, Cancionero popular de Castilla y León (Salamanca, 1989). II, núm. 27. Poseo otra versión, recogida por Susana Weich-Shahak y por mí en Hoyocasero (Ávila) el 3-10-1991, de texto muy desfigurado. 
zano de Quinto de Ebro (¿será solo casualidad que los dos únicos textos que conocemos de este episodio procedan de una edición zaragozana de 1654 y de un «dance» también zaragozano?). Su fechación es incierta, aunque hay indicios de que remonte al siglo XVII. El final de la representación se celebraba con una serie de letrillas festivas, entre las que aparece nuestro episodio, con variantes como la de «esta es la presente que la estoy dibujando» (1952) frente a «esta es la presente, que la estoy pintando» (1654) o bien «su carilla estropiada y el cuerpo andrajado» (1952) frente a «su carilla cortada y el cuerpo sajado» (1654):

\begin{tabular}{|c|c|}
\hline $\begin{array}{l}\text {.. Doña María Blasones, } \\
\text { y esposa de tres maridos } \\
\text { vevía puro, y comía asado; } \\
\text { suplica a su Eminencia } \\
\text { Esta es la presente } \\
\text { su carilla estropiada } \\
\text { en velleza es monstruo, } \\
\text { en andar un demonio }\end{array}$ & $\begin{array}{l}\text { la de los ojos sajados, } \\
\text { y todos tres fueron bagos } \\
\text { por hazer más penitencia } \\
\text { la absuelva de este pecado. } \\
\text { que la estoy dibujando } \\
\text { y el cuerpo andrajado, } \\
\text { en mirar un rayo, } \\
\text { y en lo airosa un diablo... }{ }^{15} \text {. }\end{array}$ \\
\hline
\end{tabular}

EL TÓPICO FOLCLÓRICO DEL CABALLO RIDÍCULO. SU USO SATÍRICO GENERAL. SU USO ANTIJUdíO ESPECÍ́FICO EN LOS SIGLOS XIV A XVI

No es fácil extraer conclusiones seguras de unos textos en los que predomina el dinamismo oral y cuya documentación es tan enmarañada como la que acabamos de conocer. Desde el poema de Mena analizado al principio hasta la tradición de hoy mismo, muchos son los cambios que han dejado su impronta transformadora sobre los hombres y sobre la literatura. Resulta por ello difícil - acaso imposible- saber si hay que atribuir a una relación poética efectiva o al puro azar las notables similitudes entre la venta del caballo del Arcipreste, que - según Mena y el Bachiller de Cibdareal- «coxquea de tres pies y no hinca la una mano», «cae bien a menudo» y «amagaba de meterse en todos los charcos», y la del caballo del bonetero (o del judío, cristiano, portugués

15 A. de LARRea Palacín, EL dance aragonés y las representaciones de moros y cristianos (Tetuán, 1952), pp. 95-96; ver además pp. 20-21. Derivados parciales de esta composición parecen conservarse en la tradición oral. Así, F. RodRíguez Marín publicó en Cantos populares españoles (reed. Madrid, 1981), núm. 140, un canción infantil que decía: "Yo soy doña Ana de Chaves, / la de los ojos hundidos, / casada con tres maridos; / todos fueron capitanes; / murieron en las milicias / donde murieron mis padres...» 
o gitano) que, «cojo de tres patas, manco de una mano» y tropezador en todos los charcos que le salen al paso, pervive en la tradición moderna. Respaldado además por parecida intención de invectiva social contra la casta de su dueño a la que tenía la sátira del siglo XV.

¿Pura y casual coincidencia de tópicos? ¿O conexión poética efectiva entre ambas ramas? Las coincidencias de formulación poética y de intencionalidad satírica que relacionan todos los textos parecen claras, pero no menos evidentes son sus discrepancias formales y argumentales. En el de Mena encontramos una estructura de quince coplas octosílabas de arte menor con «finida» muy distinta de la serie no estrófica del romancillo hexasilábico. Del mismo modo que su sátira, dirigida en primera persona contra el vendedor del caballo, se separa de la que se vierte en tercera persona no sobre el vendedor, sino sobre el comprador del animal en el romancillo. Su contenido anticlerical no puede considerarse, en cambio, en contraposición grave con el de El bonetero, ya que se limita a añadir una más al muestrario de pullas antijudías, anticristianas, antiportuguesas o antigitanas que se dan en las demás ramas textuales. Otras diferencias como la documentación en las Coplas del episodio del juicio al vendedor del caballo, como la aparición en algunas versiones del romancillo de las anécdotas del corte del sayo o de la moza endemoniada, o como las discrepancias en desenlaces, estribillos, etc., son también explicables desde el contexto oral en que ha vivido esta poesía, aunque no dejan de introducir nuevos elementos de duda.

Y está, para mayor complicación, la cuestión de las fuentes. Que no es nada sencilla de resolver queda claro desde el momento en que nos acercamos a la maraña de derivaciones folclórico-literarias que se conocen del motivo de la venta y ridiculez del caballo, tan explotado, por ejemplo, en la literatura clásica (de innegable raíz folclórica) de Esopo, Babrio, Plauto, Apuleyo o Luciano, por cuyas obras transitan numerosos caballos, burros o mulas llagados y cojeantes ${ }^{16}$. Se documentan sátiras análogas en todo el catálogo de diálogos, pleitos y testamentos de caballerías que nos han preservado las literaturas francesa, provenzal y catalana medievales ${ }^{17}$, y que tuvieron continuidad en algún

16 Fábulas de Esopo. Vida de Esopo. Fábulas de Babrio, ed. P. BÁdenas y J. LÓPEZ (Madrid, 1978): Esopo núm. 180, Babrio núm. 76 y núm. 111; Plauto, Asinaria o la venta de los asnos, Comedias, ed. P. A. MARTín (Madrid, 1944), vol. I, pp. 113-168: p. 134; ApUleyo, El asno de oro (VI: 30, VII: 15-18, VIII: 23); LuCIANo, Lucio o el asno, Obras, ed. J. L. Navarro (Madrid, 1988), II, pp. 320-363: p. 339.

17 P. Le GeNTIL, La poésie lyrique espagnole et portugaise a la fin du Moyen Age (Rennes, 1949-1953), I, p. 456; y J. RugGIERI, Il canzoniere di Resende (Ginebra, 1931), p. $70-71$. 
ensienplo de Juan Ruiz ${ }^{18}$ o en los cancioneros que recogen la última producción poética de la Edad Media española y portuguesa: Gómez Manrique ${ }^{19}$, los poetas del Cancioneiro geral de Resende ${ }^{20}$, Castillejo ${ }^{21}$, el comendador de la Magdalena de Salamanca ${ }^{22}$ y algún autor anónimo ${ }^{23}$ tocaron el asunto cargando las tintas sobre las tachas de la caballería, pero sin extender normalmente la sátira al caballero y a su casta social. Puede decirse que el mismo Rocinante cervantino, que «tenía más cuartos que un real y más tachas que el caballo de Gonela ${ }^{24}$ es uno de los más preclaros ejemplos de derivación de este tópico folclórico-

18 «Ensienplo del cavallo e del asno», Libro de buen amor, ed. J. JosET (Madrid, 1990), est. 242-243.

19 Cancionero, ed. A. PAZ y MeliÁ (Madrid, 1885), vol. II, núm. LXXIII (En nombre de una mula), y núm. LXXV (Razonamiento de vn roçin a vn paje): "Del todo me quebranté / corriendo sierras e llanos, / tanto que mis braços sanos / para siempre los manqué; / de guisa que caminando / ya desmayo, / e munchas vegadas cayo / tropeçando...»

20 Composiciones tituladas «De Nuno Pereyra a hũa dama da maneira que the auia de goarneçer hũa mula...» (f. CLVIv); «O macho rruço de luys freyre estando para morrer» (f. CLVII); «De Duarte d' Agama em Lixboa... por que... The cahyo hũ caualo...» (fs. CLXIXr-CLXXIIv); y «Trouas d'Anrique da Mota a hũa mula muyto magra, et velha...» (fs. CCVIv-CCIXr).

${ }^{21}$ Obras de conversación y pasatiempo, Obras, 3 vols. (Madrid, 1927), vol. II, poemas titulados Querella de un macho contra su amo... y Respuesta del señor Francisco de Salamanca, pp. 272-275; A un caballo de un amigo llamado Tristán, p. 282-287: «Y lo ojos tiene sumidos / y el pescuezo prolongado, / derramados los oidos / como orejas de un arado... / y a cada paso tropieça (vs. 1498-1506)»; Recado falso a Canseco, de parte de un concejo donde le prendieron su macho..., pp. 297-298; y $A$ un maestro mas teologo que trovador, que... hizo unas coplas a dicho macho, pp. 298-300.

22 L. Zapata, Miscelánea (Madrid, 1949), II, p. 269. Este epigrama está en J. de VALDÉs, Diálogo de la lengua (cf. ed. A. Quilis, Madrid, 1984, p. 168) y, según V. Gaos, podría haber inspirado la figura de rocinante (cf. su ed. del Quijote, Madrid, 1987, I, p. 62).

23 Ver la Satyra graciosa, y entretenida que trata de la rica almoneda que se bizo en la villa de Cartama... en M. GAUTHIER [pseud. de R. Foulché-Delbosch], «De quelques jeux d'Esprit: I», Revue Hispanique, XXXIII (1915), pp. 383-445, núm. XVI: «Sacaron a vender vn asno flojo, / flaco, viejo, anquiseco y derrengado: / el vno y otro hijar tenía matado; / ciego de vn pie, y manco de vn ojo...»

24 Don Quijote de la Mancha, parte I, cap. I. Sobre las fuentes italianas de este Gonela y su ridículo caballo, ver la ed. de A. Giannini, 4 vols. (Florencia, 1923-1927), I, cap. I, nota 14. Otras citas en la literatura española acaso se refieran a esta caballo. Por ejemplo, la de Calderón (en jerga gitanesca inventada) en su entremés La franchota: «Adóte música y la tarantela / desota la polé de la Gonela» (Entremeses, jácaras y mojigangas, ed. E. Rodríguez y A. Tordera, Madrid, 1982, pp. 252-261: vs. 114-115). 
literario universal, que no desaprovecharon autores como Góngora ${ }^{25}$, Quevedo ${ }^{26}$ ni otros que se acercan ya a la literatura moderna ${ }^{27}$ y que han escrito en paralelo a una tradición popular que ha desarrollado el mismo motivo hasta hoy ${ }^{28}$.

El peligro de extravío en semejante jungla de expresiones del tópico del caballo ridículo abruma, al menos a primera vista. Pero cuando se desciende al análisis pormenorizado es fácil descubrir que la relación de la mayoría de ellas con las demás o con el motivo universal del que derivan es absolutamente abierta y general: es cierto que todas satirizan, de un forma o de otra, a alguna caballería, pero sólo las Coplas de Juan de Mena y el romancillo de El bonetero guardan coincidencias de formulación poética, de contenido argumental y, sobre todo, de intención social que dejan abierta la posibilidad de una relación más estrecha.

Efectivamente, los requisitos de ser cojo de tres patas, manco de una mano, tropezador en los charcos y vendido o comprado mediante engaño por alguna persona de casta antipática para la voz cantante sólo los reúnen estos dos caballos, conformando una base de coincidencias - alguna vez literales - ciertamente llamativa.

El modo en que se desarrolla la sátira social en ambas ramas presenta coincidencias adicionales que podrían sugerir su dependencia de

25 Por ejemplo, en el diálogo animalístico «Murmuraban los rocines a la puerta del Palacio», o en el de "Aunque entiendo poco griego...» (ver Romances, ed. A. Carreño, Madrid, 1982, pp. 248-255 y 339-346).

26 Por ejemplo en el romance que presenta un diálogo entre «Tres mulas de tres doctores / y una haca de un barbero», en Poesía original completa, ed. J. M. BLECUA (reed. Madrid, 1981), núm. 735.

27 Merece citarse aquí un romance en bable de comienzos del siglo XVIII aludido por Rubén Darío en «Poesía asturiana», Todo al vuelo (Madrid, ca. 1920), pp. 91-99: p. 95; y editado en J. R. Olivar Faes, «'El caballo' romance en bable de don Francisco Bernaldo de Quirós», Boletín del Instituto de Estudios Asturianos, XXXIII (1979), pp. 127-152; ver además el episodio de la venta de la mula del gitano en J. AMÓS DE Escalante, Del Manzanares al Darro, Obras escogidas, ed. M. Menéndez Pelayo (reed. Madrid, 1956), I, pp. 207-316: p. 248.

28 Desde el siglo XV hasta hoy abundan los «testamentos de burros» que describen paródicamente a estos animales (cf. sobre ellos mi artículo «El Cancioneiro de Garcia de Resende, los testamentos de burros y la poesía folclórica de la Romania Occidental», en prensa). Se siguen cantando en España e Hispanoamérica romances y canciones sobre el tema. Ver de J. Vinson, Literatura popular del País Vasco, trad. y ed. I. Urdanibia (reimp. San Sebastián, 1988), pp. 110-113; J. M. de LeIZAOlA, La "crónica" en la poesía popular vasca (Buenos Aires, 1961), pp. 92-96; A. SÁNCHEZ FraILE, Nuevo cancionero salmantino (Salamanca, 1943), núm. 9; Josep Crivillé I BARGAlló, Música tradicional catalana, vol. I, Enfants (Barcelona, 1981), núms. 163 y 178; y S. FeIjoo, Cuarteta y décima (La Habana, 1980), pp. 324-325. 
una misma fábula poética, con una simple variación del sujeto de esa fábula. El maltrato al fraile en una y a personajes muy diversos en la otra es indicio del uso utilitario de un motivo cómico que se muestra dúctil a la variable intención de sus usuarios: a Mena cuando la dirige contra los frailes, y Alfay-Gracián o a los cantores cacereños cuando la vierten contra los judíos, a los judíos de Marruecos cuando se burlan con ella de los cristianos, a los castellanos cuando se ríen de los portugueses y a los campesinos fontaneses cuando la aplican a los gitanos. Extraordinario ejemplo de actualización semántica de una poesía a cuya longevidad oral no ha debido ser ajena este asombroso poder de reciclaje social.

Ahora bien, si aceptamos que todo el muestrario de víctimas de la fábula responde a usos diferentes de un mismo mecanismo poético que permite mantener el motivo satírico variando el sujeto, también podemos preguntarnos cuál sería el sujeto y por tanto el sentido original de la burla del caballo ruinoso: ¿anticlerical, antisemita, antiportugués? No es fácil precisarlo cuando todo parece indicar que su primera plasmación escrita, la de las Coplas de Mena, recoge un motivo folclórico anterior que Pérez Priego creía entroncado con la vieja tradición de diálogos animalísticos medievales ${ }^{29}$, y que a Carla de Nigris le sugería «un gioco costruito intorno a alcuni motivi tipici della poesia burlesca» ${ }^{30}$. Que las Coplas de Mena deben ser recreación de algún tópico tradicional antes que denuncia puntual de una persona y de un fraude concretos tiene el apoyo de varias claves de su poética interna. Por ejemplo, la contradicción de los nombres de «arcipreste» (v. 9), «fraile» (v. 17), y «abad» (v. 123) que recibe su inconcreto protagonista, en abierta colisión con una de las constantes más definidoras de la poesía cancioneril, que es la de la sátira con nombres, apellidos, pelos y señales de los destinatarios. O la declaración explícita del autor de que él ya «avia oido», antes de su compra, las tachas del animal, lo cual difícilmente puede cumplir otra función, en el inicio del texto, que la de reconocimiento de algún motivo inspirador para él y familiar quizás para su público.

¿Podemos entonces preguntarnos hacia qué tipo de fábula parecen apuntar todos estos indicios de alusión a algún motivo anterior dispersos en las Coplas de Mena? La respuesta, si atendemos a los tópicos folclóricos y poéticos dominantes en su época, parece orientarse en una dirección: en la de la burla antijudía, que era la que más repetidamente

29 PÉrez Priego, Juan de Mena: obra lírica, p. 42.

30 De NigRIS, Juan de Mena: poesie ninori, p. 36. 
se asociaba, entre los siglos XIV y XVI, a la sátira del mal negocio y/o de la ridiculez del caballo.

Sabemos, por ejemplo, que ya Juan Ruiz, en el siglo XIV, había situado en un contexto carnavalesco y aludido humorísticamente al caballo «con miedo» de Rabí Açelyn ${ }^{31}$. Poco después empiezan a documentarse dichos y refranes referidos, algunos de ellos, a la pérdida o al engaño del que solían ser víctimas los judíos en relación con sus cabalgaduras: «judío, haz tahula [o tabahula], sino perdido has la mula» ${ }^{32}$, y «judío a caballo es querer acaballo de perder» ${ }^{33}$; o bien a las miserias y achaques de sus animales, como los de «el cauallo del xudío, harto de agua y bien corrido» ${ }^{34}$, «el asno del judío, bien trabajado y mal mantenido» ${ }^{35}$ o «duelos tiene quien te tiene' dijo el judío a su mula» ${ }^{36}$. La ruindad de sus cabalgaduras fue tópico tan arraigado como para que la clase conversa lo heredase también de sus ancestros judíos: «A kavallero nuevo, kavallo viexo» ${ }^{37}$. Recuérdese además el motivo que casi obsesionaba a Antón de Montoro, el excéntrico Ropero de Córdoba que gustaba de burlarse de su condición de judeo-converso e insistió sobre el

31 Libro de buen amor, vs. 1184-1188. Cf. además J. L. LACAvE, «El rabí Açelyn y su posible identificación», Actas del I Congreso Internacional sobre el Arcipreste de Hita, ed. M. Criado del Val (Barcelona, 1973), pp. 479-482; y K. BRown, «Cánones eclesiásticos de Castilla en el siglo XIV y el rocín del Rabí Açelyn en el Libro de buen amor», La Corónica, XII (1983-1984), pp. 204-210.

32 M. de Santillana, Refranes que dizen las viejas tras el fuego, ed. U. Cronan [pseud. de R. Foulché-Delbosc], RHi, XXV (1911), pp. 134-219, núm. 376; H. NúÑEZ, Refranes o proverbios en romance (Salamanca, 1555), f. 60v; ms. de Refranes castellanos, (s. XVI) de Rodríguez Marín, f. 104r; y G. CORREAS, Vocabulario de refranes y frases proverbiales, ed. L. Combet (Burdeos, 1967), p. 306; L. MARTínez KLEISER, en Refranero general ideológico español (Madrid, 1953), núm. 34.744, define tababula como alhaja dada en prenda'; E. S. O'KANE, en Refranes y frases proverbiales españolas de la Edaa Media, Anejo II del Boletín de la Real Academia Española (Madrid, 1959), p. 217, propone su equivalencia a 'tahulla, medida agraria equivalente a 1.600 varas cuadradas'; y según Combet podría ser fórmula imperativa equivalente a 'judío, hazte afuera'; puede que quepan otras dos posibilidades: que tabula o tababula procedan del hb. tabbula argucia' - sugerencia de I. M. Hassán-; o que sean corrupciones de tababola 'bulla, ruido grande, batahola' (Dicc. R.A.E.).

33 El sentido con el que Rodríguez Marín explicó este refrán era el de «juego del modo adverbial a caballo y del verbo acabar» (cf. MARTINEZ KLEISER, Refranero, núm. 34.790).

3.4 P. VALlÉs, Libro de refranes (Zaragoza, 1549), f. cvii; NúñEz, Refranes, f. 42; Correas, Vocabulario, p. 100 (cf. MARTínez Kleiser, Refranero, núm. 34.734).

35 MARTINEZ KleISER, Refranero, núm. 34.735.

36 MARTÍNEZ KLEISER, Refranero, núm. 44.358.

37 Correas, Vocabulario, p. 18. 
asunto del caballo ridículo en media docena de poemas que ofrecen un retrato tan crudo de sí mismo como el de aquel debate en que su caballo le llama «maluado cohén, judío, [y] çafio», o como aquel otro en que no ocultaba su falta de escrúpulos al pretender arrendar su «mucho flaca» mula ${ }^{38}$. Hay que citar, en fin, el episodio del Auto de las gitanas de Gil Vicente en que un gitano intenta la venta del caballo del judío de manera nada ajustada a los convencionalismos de este mercadeo, lo que nos pone sobre aviso de parodia de alguna referencia cultural con la que su público debía estar familiarizado:

¿Quál de vuzotroz, siñurez,
trocará un rocín mío,
rocín que huve d' un judío
ahora en pascua de flores?
$\ldots \ldots \ldots \ldots \ldots \ldots \ldots \ldots$
Oh, ceñurez cavalleros,
mi rocín tuerto os alabo,
porque es calçado 'n el rabo,
zambro de los piez trazeros.
Tiene el pecho muy hidalgo
y cocea al cavalgar ${ }^{39}$.

Que Mena conoció la sátira que en la España pre y renacentista ridiculizaba a los judíos con motivo de las tachas de sus cabalgaduras es indudable. Que esa sátira fuese la que él «avia oido» y la que habría hipotéticamente tenido en cuenta en el momento de componer sus $\mathrm{Co}^{-}$ plas, dotando su poema de un sentido anticlerical en vez de antijudío, o más bien de un sentido anticlerical a la par que antijudío, es, por tanto, una posibilidad atendible, sobre todo en una época en que estaban en el aire dichos y opiniones que tendían a igualar la propensión de ambas castas a la avaricia y a la usura ${ }^{40}$. Y sobre todo también ante

38 Cancionero, ed. F. CANTERA y C. Carrete (Madrid, 1984), poemas titulados "Quexos de vna mula...» (núm. 73); «A don Pedro de Aguilar, porque le mando vn caballo...» (núm. 76), «A un alcalde, dando quexa de vno que se llamaua Calamar, porque le alquilo vn roçin...» (núm. 88); "Alfonso de Velasco, que quería mercar vna mula...» (núm. 89); «Otra suya a Gonçalo de Hoçes, diziendole que le trocasen vn machon famoso que tenia...» (núm. 110); «Otra del ropero a su cauallo...» (núm. 116).

39 Auto de las gitanas, en Obras dramáticas castellanas, ed. T. R. HART (3." ed. Madrid, 1975), pp. 229-236: vs. 25-28 y 38-42.

40 Cf. por ejemplo los refranes «xudío para la merkaduría, i fraile para la ipokresia» (CORREAS, Vocabulario, p. 306); «fraile ni Iudío, nunca buen amigo» (NúÑEZ, Refranes, f. 53; CORREAS, Vocabulario, p. 341); y «[líbrenos Dios] de fraile rebozado, y de judío acosado, y de hambriento soldado» (NÚÑEZ, Refranes, f. 34, F. RodRíGUEZ Marín, Más de 21.000 refranes castellanos, Madrid, 1926, p. 109). 
elementos de poética interna de las Coplas, tan ambiguos como las pullas por estar «en un retablo pintado por homarrache», más achacables a los siniestros judíos de los «Ecce-homos» que a un fraile a quien Mena no sabemos qué motivo podía tener para haber visto pintado en un retablo. Advirtamos, ahora bien, que si seguimos por este camino de apurar el descifrado del doble lenguaje que informa muchos elementos de las Coplas podemos llegar a terrenos tan resbaladizos como el de la hasta ahora baldía polémica sobre el ascendiente converso de Mena ${ }^{41}$, por lo que bien pudiera ser lo más prudente abandonar aquí esta pista y dejar formulado como simple supuesto, bien que autorizado por la cultura ambiente y por la ambigüedad de tono de las Coplas, el de su posible interpretación antijudía.

\section{EL ANTIJUDAÍSMO ORIGINARIO DEL ROMANCILLO DE EL BONETERO}

Lo anterior enlaza con la intención antijudía que parece que también debió guiar al romancillo. Recordemos que Catalán y Cid defendían su carácter antisemita, afirmando que su composición hubo de ser respuesta a la entrada de conversos portugueses en España en el segundo cuarto del siglo XVI. En mi opinión, este hecho pudo dejar su impronta actualizadora en el romancillo, según prueban las versiones zamorana y leonesas que llaman portugués al bonetero. En igual medida que la malquerencia a cristianos o a gitanos dejó su marca actualizadora en las versiones marroquí o fontense que tachan de cristiano o gitano al comprador de la mula. Pero sus rasgos poéticos denotadores de una intensa vida oral anterior a su documentación en 1636 y en 1654, además de sus coincidencias literales y de contenido con toda una tradición poética y folclórica anterior me parecen sugeridores de que el romancillo de El bonetero era ya viejo cuando lo recogieron Calderón y Alfay-Gracián. $\mathrm{Y}$ que las alusiones personales y toponímicas (a Octanès, Morales, la Trapería, etc.) que Catalán y Cid consideraban referentes a hechos y personajes recientes y conocidos, no dejan de ser motivos actualizadores como los de Cristóbal, Gervasio y Gaspar lo son en las versiones de Fuente del Maestre.

La antigüedad de los tópicos antisemitas que informan las versiones barrocas me parece que apoyan este supuesto. Sabemos que mucho antes de su alusión en la versión de 1654, el motivo de la trapería tenía

4l Ver sobre el asunto los comentarios y bibliografía de Pérez PrIEgo en Juan de Mena: obra lírica, pp. 4-5. 
connotaciones antijudías ${ }^{42}$. También la profesión de sastre del protagonista del romancillo se asociaba a los judíos desde antiguo ${ }^{43}$. La actividad confeccionadora de sayos juega además con el viejo doble sentido antisemita de la identificación de los sayones (verdugos públicos) con los judíos (tachados popularmente de verdugos de Cristo) ${ }^{44}$. Ello refuerza, dicho sea de paso, la tesis de Catalán de que el episodio del corte del sayo que aparece en la versión de 1654 y en algunas sefardíes pertenece al núcleo original del romancillo. El episodio de la moza endemoniada que sólo aparece en la versión de Alfay-Gracián, me parece en cambio espúreo, ya que apenas dispone de soldadura argumental con el resto de la fábula y sabemos que aparece interpolada en alguna otra obra, como en el dance de Quinto de Ebro.

Todo parece indicar, en definitiva, que el círculo donde coinciden las formulaciones y los tópicos compartidos por el poema de Mena y por el romancillo se estrecha también en torno a esta clave antisemita del tópico de la cabalgadura ridícula, que evidentemente no ignoraba y que acaso fuera el que «avia oido» e inspirado al autor de las Coplas,

42 Así lo evidencia F. Delicado cuando en La lozana andaluza de 1528 (cf. la ed. de C. Allaigre, Madrid, 1985, p. 202) ponía este motivo en boca de judíos españoles exiliados en Roma:

BEATRIZ: Mi hermana la viuda vino casada con un trapero rico.

LOZANA: ¿Y cuánto ha que estáis aquí?

BEATRIZ: Señora mía, desde el año que se puso la Inquisición.

43 Sobre la identificación tópica de judíos y sastres, ver mi artículo «El juego renacentista de El peral de las peras en la tradición sefardí de Rodas», en mi tesis Correspondencias hispánicas del cancionero sefardi de Oriente: estudios comparativos (Madrid, 1992). La mala fama de los sastres llegó a hacer que se acuñasen insultos como el de «cara de sastre» (cf. Quevedo, Poesía, núm. 788, v. 134) y cancioncillas como la que glosa Castillejo, en Obras, II, vs. 510-11: «Por mi mal os vi yo, sastre, / que por vos salgo al pregón.» Sobre la mala fama de los boneteros, oficio asociado al de sastre, ver A. EnRíquez de GuZMÁn, Libro de la vida y costumbres, ed. H. Keniston (Madrid, 1960), p. 256.

44 Puede citarse, a este respecto, el «Romance de Monçon» (cf. Cancionero de Juan Fernández de Ixar, 2 vols., ed. J. M. Azáceta, Madrid, 1956, vol. II, pp. 768-771; y L. Zapata, Miscelánea: silva de cosas curiosas, ed. A. Rodríguez-Moñino, Madrid [1931], p. 139), que ataca al «sastre que con malas tijeras / está cortando un sayón». Abundan las referencias análogas en todas la literatura áurea, sobre todo en Quevedo, que en la letrilla satírica «Deseado he desde niño» (Poesia, núm. 653, v. 8) confunde intencionadamente los términos «sayo» y «sayón» («un sayón con pantorrillas») y que en el soneto «Yo te untaré mis obras con tocino» (Poesía, núm. 829, v. 14), en que ataca a Góngora por judío, le acusa de tener «de sayón la rebeldía»; ver también Poesía, núm. 513, v. 7; y Poesía, núm. 803, v. 22. 
en la misma medida en que fue también conocido, recogido y utilizado por los paremiólogos y poetas de su siglo y del siguiente.

\section{CONCLUSIONES}

Con esto quedamos en mejor posición que al principio para contestar a las preguntas planteadas. ¿Son síntoma de relación poética las coincidencias que se dan entre las Coplas del siglo XV, las cartas apócrifas del Bachiller de Cibdareal del XVII y el romancillo documentado de entonces a esta parte? Y de ser así, ¿serían las Coplas fuente inspiradora del romancillo, o podría ser a la inversa, que aludan las Coplas a alguno de los tópicos de éste, si damos por posible un prolongado período de latencia oral del romancillo anterior a su primera documentación barroca? ¿O bien nos encontramos, como tercera posibilidad, ante manifestaciones genéticamente independientes de un tópico folclórico común?

Considerada con los debidos reparos esta última opción, por poco compatible con todas las coincidencias - de formulación, argumento e intencionalidad - que hay entre las Coplas de Mena y el romancillo de El bonetero, debemos aceptar también que la posibilidad de que las coplas de arte menor de Mena evolucionasen hacia la forma del romancillo hexasilábico no encuentra apoyo en la tradición textual, que no muestra indicios de tradicionalidad ni de apreciable evolución oral de los textos de las Coplas, reimpresos entre 1512 y 1582. En cambio, la posibilidad de que éstas recogiesen al menos dos versos («el coxquea de tres pies / y no hinca la una mano») y aludiesen y transformasen el motivo del romancillo o de un antecesor cercano del romancillo sí que puede hallar justificación - aunque no segura confirmación- en el entramado documental y cultural en que se insertan. Por razones como la de los síntomas de antigua vida oral de los testimonios áureos del romancillo; el viejo arraigo, desde mucho tiempo antes, de la burla antijudía asociada a los motivos del caballo ridículo, del oficio de sastre y de la trapería; la comprobada solera literaria del metro del romancillo hexasilábico ${ }^{45}$; y la inveterada costumbre de los autores de la época de aludir, glosar y recrear de forma más o menos ambigua motivos de la tradición heredada. Todas éstas son razones que dejan abierta la posibilidad de que el romancillo de El bonetero, anterior a todas luces a la fecha de su primera recolección de hacia 1636, pudiera haber sido co-

45 R. Menéndez Pidal, Romancero hispánico (Madrid, 1953), 2 vols., IV: 4, 17, 19, 20; XIII: 9 y XX: 4 . 
nocido y usado como fuente inspiradora de algún motivo de las Coplas de Mena.

La densidad simbólica y la ambigüedad de lenguaje que parecen informar muchos motivos de las Coplas y del romancillo no permiten, sin embargo, confirmar esta opción. Pero aún admitiendo su margen de error y la posibilidad de que sus coincidencias fueran casuales, algo vendría a establecer, aunque fuera a posteriori, una cierta relación: el hecho de que, cuando el falso Bachiller de Cibdareal se inventó en el siglo XVII su apócrifo epistolario quinientista, él también "creyó» que el caballo de Juan de Mena era el mismo que el del Bonetero: sólo así se entiende su «lapsus», por asociación mental involuntaria, de atribuir al caballo de Mena la inclinación a «meterse en todos los charcos, e tropezador de a cada diez estropiezos enfilar una caída» que no se menciona en las Coplas pero que es motivo recurrente en el romancillo. Ello evidencia la maravillosa ironía de un epistolario compuesto para engañar y confundir que contribuye, muy en contra de sus propósitos, a aclararnos el problema de las relaciones entre dos tipos de textos que a través de él $-\mathrm{O}$ de su asociación mental subconsciente- estrechan su comunicación.

\author{
José MANuel Pedrosa \\ Instituto de Filología \\ CSIC. Madrid
}

La fábula de un caballo cojimanco, tropezador y vendido engañosamente a una persona cuya casta social se satiriza, informa unas Coplas de arte menor compuestas por Juan de Mena en el siglo Xv y un romancillo hexasílabo documentado en la tradición oral desde el siglo XVII hasta la actualidad. Sus coincidencias formulísticas, argumentales y de intención social sugieren, aunque no prueban definitivamente, su conexión poética. Un epistolario apócrifo del siglo XVII que confunde involuntariamente ambos tipos de textos, el literario y el oral, refuerza también su posible relación poética.

The fable of a ridiculous horse - lame, armless, stumbling and fraudulently sold to a person whose social caste is satirically described- makes the subject of some Coplas that were composed by Juan de Mena in the XVth century, and of an hexasyllabic «romancillo» that was documented in oral tradition from XVIIth century onwards until our time. Their formulistic, subject and social purpose coincidences suggest, although without any definite proof, their poetic interrelationship. An apocryphal XVIIth century collection of letters that unintentionally mixes up both types of texts - the literary and the oral one- also reinforces their possible poetic links. 